\title{
Exploring Lay People's Beliefs about Psychology in the United Kingdom (UK)
}

\author{
Okoloba, Maia M., \& Ogueji, Ifeanyichukwu A. \\ ${ }^{1}$ The University of Buckingham, Department of Psychology, Yeomanry House, Buckingham, \\ Buckinghamshire, United Kingdom. \\ ${ }^{2}$ Department of Psychology, University of Ibadan, Ibadan, Oyo state, Nigeria. \\ Correspondence: Ogueji, Ifeanyichukwu A. \\ Email: ifeanyiogueji21@gmail.com
}

Doi: $10.23918 /$ ijsses.v7i2p40

\begin{abstract}
In literature, false beliefs about what Psychology as a discipline entails remain a recurrent issue among lay persons. There is thus the need to explore the beliefs that are held about Psychology among lay persons, and develop interventions that are tailored towards the false beliefs in lay persons. Therefore, this research used semi-structured interviews to explore the beliefs of five (5) individuals who were considered as lay people in relation to Psychology in the UK. During thematic analysis, three (3) themes were created. They were; mind readers, a discipline with less recognition, and mental health profession. The need for appropriate information sharing, and evidence-based campaigns about what Psychology as a discipline entails was thus recommended, targeting the general population of lay people.
\end{abstract}

Keywords: Lay People, Beliefs, Psychology, UK.

\section{Introduction}

One discipline that has often been criticised by lay persons as being a pseudoscience is Psychology (Lilienfeld \& Gurung, 2012). The discipline of Psychology is often misinterpreted within the general population of lay persons, and this is sometimes as a result of embedded myths believed despite a lack of evidence supporting claims (Kowlaski \& Taylor, 2009). Some studies have consistently demonstrated that the beliefs that lay persons have about Psychology play a very key role in the growth and acceptance of Psychology in the society (Maynard 2014; Ogueji \& Constantine-Simms, 2019). Despite this, not enough studies have been conducted on the beliefs held about Psychology among lay persons.

In the UK, United States of America (USA), and some other countries, Psychology has recorded several contributions towards development by providing jobs for professionals in the area of mental health, forensic setting, or academia (The UK's Economic and Social Research Council, et al. 2009; Trapp, et al. 2011; Motyl, et al. 2017). Although Psychology has contributed to development in the UK for instance, there are still arguments in literature that suggests the need to improve the relevance of Psychology in the UK, by exploring the beliefs held about Psychology among lay people (Furnham \& Telford, 2012; Cusimano, \& Goodwin, 2019). Therefore, the aim of the current study is to explore the beliefs held about Psychology among lay persons in the UK.

\section{Related Studies}

Benjamin, (2006) argued that false beliefs surrounding what Psychology as a discipline entails remains a recurrent issue among lay persons, with not enough research attention given to this recurrent issue. These 
false beliefs amongst the lay persons is very dangerous as it can often result in more individuals afflicted by mental illness being less likely to seek mental health services due to false beliefs about the relevance of Psychology in mental healthcare (Lilienfeld \& Gurung, 2012; Ogueji \& Constantine-Simms, 2019; Coker, et al. 2019; Ogueji \& Okoloba, 2020). It has also been suggested that false beliefs about Psychology among lay persons could also be impacting the funding of Psychology (Price, 2011), thus resulting in undiscovered potential achievements which could advance Psychology as a field.

In some other studies, the beliefs held about Psychology among lay persons has been found to be associated with what the media portrays about Psychology (Ferguson, 2015; Lilienfeld, \& Gurung, 2012; Arkowitz \& Lilienfeld, 2010; Rosen et al, 2003). Going further, scholars in other continents have demonstrated the havoc that the false beliefs held about Psychology among lay persons can pose to the development of Psychology in the society (Mefoh, 2014; Ogueji \& Constantine-Simms, 2019; Osinowo, 2016). These scholars also opined that beliefs held about Psychology by lay persons included misconceptions about the roles/duties of psychologists, and work settings where psychologists can work. In addition, the beliefs were influenced by poor awareness about what Psychology as a discipline entails.

In order to mitigate the false beliefs held about Psychology among lay persons, giving further voices to lay persons to describe what Psychology as a field entails has often been a suggested point for later studies (Ferguson, 2015; Lilienfeld \& Gurung, 2012; Ogueji \& Constantine-Simms, 2019). Therefore, given all above literature, there is the need to explore the beliefs held by lay persons about Psychology, in order to provide appropriate intervention that is tailored towards the false beliefs that are held by this population of interests. The following research question was thus highlighted:

\section{Research Question}

What beliefs about Psychology are held among lay persons?

\section{Theoretical Framework}

Given above related studies, and the question asked in the current study, we will draw insights from the behaviourism theory. According to this theory, much of peoples' beliefs or learnings is a function of their interaction with their environments (McLeod, 2015). Thus, we expect that much of the beliefs about Psychology that will be found among participants in this study will be as a result of their interaction with their environments. For instance, participants' interactions with the media, or participants' interactions with friends/strangers.

\section{Methods}

\subsection{Design}

This qualitative study employed a semi-structured interview to explore the psychological beliefs of lay people. A thematic analysis was also conducted to explore the themes in the interviews. Thematic analysis was purposely chosen for the fact that it was in line with literature's suggestion for data analysis in the current study (Peel, 2020). 


\subsection{Participants}

The study consisted of five (5) participants who were acquired by opportunity sampling at the University of Buckingham. The study required that willing participants were not involved in Psychology in any way. Below is a short summary of the participants' demographic details outlined.

Table 1: showing short demographic summary of participants

\begin{tabular}{|c|c|c|c|c|}
\hline Name (Alias) & Age & $\begin{array}{l}\text { Continent of } \\
\text { Origin }\end{array}$ & Location & Occupation \\
\hline Jake & 21 & Asia & Buckingham & $\begin{array}{l}\text { Finance } \\
\text { Student }\end{array}$ \\
\hline Isaac & 23 & Asia & Buckingham & $\begin{array}{l}\text { Store } \\
\text { Assistant }\end{array}$ \\
\hline Max & 20 & Africa & Buckingham & $\begin{array}{l}\text { Business } \\
\text { Student }\end{array}$ \\
\hline Phil & 29 & Africa & Buckingham & $\begin{array}{l}\text { Finance } \\
\text { Student } \\
\text { Business }\end{array}$ \\
\hline Ishmael & 18 & $\begin{array}{l}\text { South } \\
\text { America }\end{array}$ & Buckingham & Student \\
\hline
\end{tabular}

\subsection{Materials}

For this study, a semi-structured interview was utilized to collect data. The interview focused on asking participants to talk about their beliefs on Psychology. The central questions were a) "Have you heard about Psychology before?" b) "When I say Psychology, what image comes to your mind?". Before, conducting this study, the semi-structured questions were validated by two professors of Psychology in the Department of Psychology, the University of Buckingham, U.K., and four non-Psychology students in the University of Buckingham, U.K. The non-Psychology students were not among the respondents in our main study, and they were selected from other departments that were not designated for this study. The validation was done to ensure the appropriateness of the semi-structured questions for this study.

\subsection{Procedure}

Ethical approval for this study was received from the Research and Ethics committee of the University of Buckingham, as it met the British Psychological Society (BPS) guidelines. Likely participants were briefed about the study purpose. Those that were willing expressed consent (verbal \& written), and were enrolled in the study. The study was conducted within comfortable settings, which included quiet classrooms and a local café, and each interviews generally lasted between 20 and 25 minutes. All interviews were recorded using a phone device. Response bias was minimized by ensuring that no personally identifiable information was requested from participants throughout the study.

Confidentiality of information was maintained throughout the study, and participants were free to decline participation at any point of the study, with no consequence if they chose to do so. After the study, all 
participants were thanked for their willing participation in the study. Collected data was subjected to thematic analysis as outlined by Braun and Clarke (2006). Both authors were involved in collecting and analysing data based on their experiences in conducting similar analysis.

\section{Results}

This section presented the themes created in the qualitative data after conducting the thematic analysis. These theme are as follows:

\subsection{Mind readers}

This was the first theme showing that some participants had beliefs that Psychology entails mind reading.

For instance, after asked the question, Phil laughed and stated that psychologists are mind readers.

“(Laughs) Mind readers. Psychics, mind readers. Yeah that's it.” (Phil, age 29 years).

Max supported by reporting thus:

"Psychologists, they deal with people's minds and if you read people's minds too much maybe they start playing with your mind too." (Max, age 20 years).

\subsection{A discipline with less recognition}

This was the second theme which showed that participants submitted their beliefs about Psychology as a discipline with less recognition. For instance, Ishmael said that:

“...To me, Psychology is a discipline that isn't seen as a key occupation.” (Ishmael, age 18 years).

Another participant, Isaac supported this theme by pointing to a lack of recognition of Psychology in the African context.

"It's very overlooked in a lot of cultures, a lot of cultures don't recognise the importance of Psychology or even the existence of Psychology... Especially in African cultures where I think they don't recognise the importance of Psychology, they don't see the point of Psychology in society..." (Isaac, age 23 years).

Phil also said that:

"I've never met anybody telling me they're going to see a Psychologist for whatever reason...Thus, Psychology may be less recognized as a discipline" (Phil, age 29 years).

\subsection{Mental Health Profession}

This was the last theme, showing that a participant opined that Psychology is a mental health profession. For instance, psychologists can deliver mental health services for people with depression or people who are suicidal. An illustrative example of this theme was submitted by Jake: 
“...um you could be under pressure, committing suicide or you have depression or you're cutting yourself or something like that but you're unable to share it with a general person. Just being able to share with a psychologist helps..." (Jake, age 21 years).

\section{Discussion}

From the research, three (3) major themes were created: Mind readers, a discipline with less recognition, and mental health profession. The first theme; mind readers, demonstrated that participants had beliefs that Psychology entails mind reading. These participants opined that psychologists engage in reading the minds of others. In the second theme, we found that some participants stated their beliefs about Psychology that as a discipline, Psychology has not gained enough recognition. For instance, a participant here mentioned that he has never heard anyone telling him that he/she was going to see a psychologist for whatever reason.

The last theme showed that, a participant reported Psychology as a mental health profession. For instance, the participants here mentioned that seeing a psychologist maybe helpful for people who are suicidal or people with depression. Therefore, all three (3) themes found in this study were in line with related studies where identical themes have been mentioned (Arkowitz \& Lilienfeld, 2010; Benjamin, 2006; Lilienfeld, \& Gurung, 2012; Ferguson, 2015; Osinowo, 2016; Ogueji \& Constantine-Simms, 2019). Furthermore, the themes which emerged in the current study could have been influenced by participants' interactions with their environments (McLeod, 2015), for instance, what the media portrays about Psychology, or random conversations that our participants might have had in past or recent times. This interaction between participants and their environment is an agreement with the behaviourism theory that guided our current study.

Finally, the findings in the current study are not without implications. For instance, the fact that most participants in this study submitted that Psychology is either about mind reading or is less recognized, would suggest that such beliefs could hinder the positive impacts that Psychology as a discipline could have on these participants. In other words, such beliefs could limit these participants from benefiting from the relevance of Psychology in the society because of the fact that their beliefs are not completely accurate.

\section{Limitation of Study}

Although this study required that participants had no contact with Psychology, we cannot neglect the fact that our participants might have been previously involved with Psychology, perhaps through Psychology related textbooks, the media, or through conversations with friends/strangers in past times. Another limitation of our study was the small sample size. However, literature has argued that the sample size in the current study is adequate to supply the themes needed in the current study (Dworkin, 2012).

\section{Recommendation and Conclusion}

The study concluded that the false beliefs held about what Psychology as a discipline entails remain a recurrent issue in lay persons. Therefore, we recommend the need for appropriate information sharing and evidence-based campaigns about what Psychology as a discipline entails. 
The appropriate information sharing and evidence-based campaigns should be designed to target the general population of lay persons, considering the themes found in this study.

\section{Acknowledgement}

Research and Ethics committee of the University of Buckingham, UK for approving this study, and to the participants for their willingness to participate in this study.

\section{Conflict of Interest}

There is none to declare.

\section{References}

Arkowitz, H., \& Lilienfeld, S, O. (2010). The "Just do it" trap: Why radio "does" help few. Scienetifc American Mind.

Benjamin, L, T. (2006). Why are we keeping Psychological science a secret. In Invited address at the annual convention of Association for Psychological Science. New York, Ny.

Braun, V., Clarke, V. (2006). Using the thematic analysis in psychology. Qualitative Research in Psychology, 3, 77 - 101.

Coker, O., Olibamoyo, O., Adewunmi, A. O., Osakwe, V. A., Taiwo, T., \& Alonge, A. O. (2019). Help-seeking behaviors of individuals with mental illness before pursuing professional mental health care services in Lagos, Nigeria. International Journal of Advanced Community Medicine, 2(1), 10-16.

Cusimano, C., \& Goodwin, G. P. (2019). Lay beliefs about the controllability of everyday mental states. Journal of Experimental Psychology: General, 148(10), 1701-1732

Dworkin, S. L. (2012). Sample size policy for qualitative studies using in-depth interviews. Arch Sex Behav, 41, 1319-1320.

Ferguson, C, J. (2015). Everybody knows psychology is not a real science: Public perceptions of psychology and how we can improve our relationship with policymakers, the scientific community, the general public. American Psychologist, 70(6), 527 -542.

Furnham, A., \& Telford, K. (2012). Public attitudes, lay theories, and mental health literacy: The understanding of mental health, mental illnesses - Understanding, prediction and control. Prof. Luciano I. Abate (Ed.), ISBN: 978-953-307-662-1.

Kowalski, P., \& Taylor, A, K. (2009). The effect of refuting misconceptions in the introductory psychology class. Teaching of Psychology, 36, 153 - 159.

Lilienfeld, S, O., \& Gurung (2012). Public scepticism of psychology: Why many people perceive the study of human behaviour as unscientific. American Psychologist, 67, $111-129$.

Maynard, D. (2014). The history and current status of psychology in Barbados: Research and professional practice. Interamerican Journal of Psychology, 47(2), 227.

McLeod, S. Psychological theories. Retrieved from 2015; https://www.simplypsychology.org/depression.html

Mefoh, P. (2014). Challenges and prospects of psychology in Nigeria. European Journal of Social Sciences 42(1), 57-64.

Motyl, M., Demos, A., Carsel, T., Hanson, B., Melton, Z., Mueller, A., Prims, J., Sun, J., Washburn, A., Wong, K., Yantis, C., \&Skitka, L. (2017). The state of social and personality science: Rotten to the core, not so bad, getting better, or getting worse? Journal of Personality and Social Psychology, 2017; DOI: 10.1037/pspa0000084. 
Ogueji, I. A., \& Constantine-Simms, D. (2019). "Clinical Psychology in Nigeria: An Assessment of Perceptions of the Growing Subfield among Non-Mental Health Professionals and Recommendations For Growth Acceleration." IOSR Journal of Humanities and Social Science (IOSR-JHSS). vol. 24 no. 10, 2019, pp. 25-31. doi:10.9790/0837-2410122531

Ogueji, I. A., \& Okoloba, M. M. (2020). Seeking professional help for mental illness: A cross- cultural mixed methods study of Black families in United Kingdom and Nigeria.

Osinowo, H. O. (2016). The promising baby called Psychology. Retrieved from https://www.ui.edu.ng/content/abstract-professor-helen-oosinowos-inaugral-lecture.

Peel, K. L. (2020). A beginner's guide to applied educational research using thematic analysis. Practical Assessment, Research and Evaluation, 25, 2.

Price, M, P. (2011). Promoting psychology as a STEM discipline. Monitor on Psychology, 42(2), 32-36.

Rosen, G, M., Glasgow, R, E., Moore, T, E. (2003). Self-help therapy: The science and business of giving psychology away. In S.O. Lilienfeld, S.J. Lynn, \& J.M. Lohr (Eds), Science and pseudoscience in clinical psychology (pp. 399 - 424). New York: Guilford Press.

The UK's Economic and Social Research Council, et al. (2009). International benchmarking review of UK Psychology. Retrieved from, https://esrc.ukri.org/files/research/research- and-impactevaluation/international-benchmaking-review-of-uk-psychology/

Trapp, et al. (2011). The future of undergraduate Psychology in the UK. Retrieved from, https://www.reserchgate.net/publication/265432917 